\title{
Behavioral Disorders or Parenting Deficit?
}

\author{
Martha A. Delgado-Ochoa*, Carlos Delgado-Hernandez and Luis A. Ocaña-Hernandez \\ Hospital General de Tijuana / Neuromedica
}

*Corresponding author: Martha A. Delgado-Ochoa, 9927-C Francisco Goitia Street, Zona Urbana Rio, Tijuana, Baja California. C.P. 22010, México.

To Cite This Article: Martha A. Delgado-Ochoa, Behavioral Disorders or Parenting Deficit?. 2020 - 7(3). AJBSR.MS.ID.001142.

DOI: 10.34297/AJBSR.2020.07.001142.

Received: 眥 January 24, 2020; Published: 畊 February 12, 2020

\begin{abstract}
Mexico has been doing important research in neurodevelopment, nutrition and parenting. So, we have put interest in not only diagnosing behavioral disturbances, but also in investigating the environments and the influence of caregivers on the behavior of children. An observational, descriptive and transversal study was made in patients who attended a neuropediatric consultation due to a conductual problem. We performed an exhaustive anamnesis, applied a DSM IV / 5 based questionnaire on symptoms and asked if there was a parenting structure at home. Is there any reason to believe that we are over diagnosing behavioral problems and underestimating comorbidities or child rearing problems? The results showed that almost half of the included patients did not meet criteria for a neurobiological or neurodevelopmental disorder, therefore it is the group of patients who are at risk of being over diagnosed and probably the behavioral problem is influenced by an unfavorable environment or lack of positive stimuli.
\end{abstract}

\section{Introduction}

Behavioral problems areone of the main causes of neuropediatric consultation and gradually there has been an increase in the diagnosis of ADHD (Attention deficit hyperactivity disorder) and associated disorders. The reason why this study was done is due to the fact that during my clinical practice I have noticed that preschool children have been referred by teachers, psychologists or by parents themselves for a neuropediatric consultation with the assumption of having attention deficit disorder or some other neurobiological disorder and wanted to be medicated in order to improve their behavior. We know that gradually there has been an increase in the diagnosis of ADHD, which remains eminently clinical, which makes it of high importance for an adequate evaluation in order to provide a successful treatment.

\section{Concept of Conduct}

Usually we use two words, conduct and behavior, which although conceptually are almost synonymous, clinically have different values. The word 'CONDUCT by its etymological meaning of the Latin conductus, means 'driven or guided'; Something external. BEHAVIOR of Latin comportare, means 'to imply', which entails greater involvement of the subject. And another concept to take into account is the already established genetically the TEMPERAMENT.

Thus, a behavioral disorder could manifest itself as those situations, psychopathologically unstructured, in which the child himself has a capacity for response and is even fully autonomous in his resolution [1]. Predicting that, in a timely manner, a good molding of caregivers, especially parents, will guide behavior so as not to manifest a behavioral problem.

\section{Concept of Rearing}

According to the dictionary of the Royal academy of the Spanish language: Rearing, It is said of a thing or a living being: Origin, produce something. Nurture and feed the child educate, educate and lead. Feed, care and feed birds or other animals. Organizing these words, ideally Parenting is: Taking care of a child until he becomes an adult; promoting the learning of discipline, good education, respect for others, responsibility and independence.

\section{Rearing mistakes}

The family or its variants, who are in charge of raising a child, must have a clear responsibility for what it implies, and this is to provide a harmonic, loving, safe, organized environment and 
must be the facilitator of social adaptive behavior. We must take all necessary measures to ensure that adults do our work well not to tip, facilitate or leave unnoticed the development of behavioral problems in children.

Parents should be consistent with the example we give every day, especially at home, understanding that being consistent is doing what is said and saying what is thought; If we are not consistent, the message we give is that we are not honest. Therefore, the mental health or the psychopathology of the parents themselves are of great importance and could be a reflection of the emotional or behavioral characteristics of the children.

Parenting practices that parents use may have certain responses in children's behavior. To cite some, negative affect, non-physical punishment, authoritarian control and emphasis on achievement; could have as a consequence a greater probability of presenting externalized and internalized behavioral problems. Some other scales predict dysfunctional parental practices in 3 subscales: laxity, overreaction, and verbiage [2] and each parent's dysfunctional behavior predicts specific behaviors. For example; negative affect predicts aggressive behavior, attention and behavior problems; authoritarian control predicts anxiety / depression and the emphasis on achievement predicts anxiety / depression and social problems [2-4], inhibitory behaviors produce indecision; the ignorance of the role of parents, ambivalent behavior or very tolerant, are molding tyrant children. Another aspect out of control in the current practice since the mothers also work outside home, is the little time of coexistence and quality with the children and this is accompanied by a feeling of guilt and with this in turn the overprotection, Which causes children a constant lack of initiative, insecurity and low self-esteem. And speaking of self-esteem, since it is related to achievements not so much with potentialities, both overprotection and indifference, can have negative effects on it and remains until adulthood [5-6]. At this stage neurobiological changes occur and will control the behavior, the emotions and the selection of connections necessary to integrate the intellect, because In preschool children, the brain is "under construction" [7]. That is why it is important to correct parental attitudes that can negatively shape the behavior, as well as provide the stimulus and appropriate environment according to the stage of learning in which the child is, so that we unfairly avoid diagnosing a neurobiological disorder or administer medications other than the timing or when it is unnecessary. At this age pharmacological treatment should be initiated only in the case that psychoeducational interventions have not provided substantive benefits [8].

\section{Effective parenting}

The recommendation is five effective parenting practices: encouragement, discipline, monitoring, problem solving and positive involvement with care and care. [3] Intervention according to age, habits from even before birth, to delegate responsibilities
According to their maturity, are making a difference in good breeding practices. We can no longer treat a 1-year-old as if he were a newborn, or a 4-year-old as if he were 2 years old; As well as we cannot afford to cradle babies of thirty or forty years at home.

\section{Neurobiological causes}

Are all behavioral disorders a consequence of mistakes in parenting? No. There are behavioral disorders in which there are known causes or not, of biological origin. The anatomical and functional development of the brain since its early stages in neurulation, development of the brain, until proliferation and neuronal migration; requires nutritional and emotional contributions; as well as after initiation of myelination, which may last up to about 21 years of age, requires, in addition to nutritional and emotional contributions, appropriate stimulation according to the subject's age, mainly in the first years of life.

\section{Functional cerebral anatomy}

The executive center of the brain is located in the frontal lobe, the largest lobe, in charge of motor control, movement planning, articulation of language, theory of mind, executive functions, motivational and behavior. The divisions of the frontal lobe are: Orbitofrontal, dorsolateral and frontal mesial. The orbitofrontal is in charge of the processing and regulation of the emotions, its alteration causes disinhibition and euphoria. The lateral dorsum is in charge of the executive functions, its alteration will produce apathy, slow and unmotivated attitudes. The frontal mesial is the one in charge of the effort and attentive regulation and the mentalization reason why its alteration will cause distractibility.

The neurotransmitters that participate are Dopamine as mediator of attention and movement, therefore its deficiency causes Inattention and hyperactivity. Norepinephrine modulates mood, its deficiency will produce depression and anxiety. Serotonin modulates behavior and regulates sleep, its deficiency will cause aggressiveness, impulsivity and sleep disorders [9]. The participation of other neurotransmitters such as $\mathrm{N}$-acetyl aspartate and glutamate, which in turn regulate dopamine, has been described [10].

\section{Clinical Evaluation}

Behavioral evaluation remains largely clinical. Genetic, neuroimaging and neurofunctional studies do not yet have pathognomonic relevance, although in the near future they will be essential [1]. Although magnetic resonance and functional neuroimaging studies suggest structural and functional alterations in the striated fronto circuits, the cerebellum, corpus callosum and the temporal parietal cortex, volumetric reduction of the cerebellar vermis, splenius of the corpus callosum, right caudate nucleus and volume cerebral hemisphere and right hemisphere. Decreased gray matter in the right frontal gyrus, thinning of the dorsolateral and prefrontal cortex [11,12]. 
Due to the fact that evaluation remains eminently clinical, we can empirically simplify behavioral problems such as: internalised (depression, anxiety, isolation, somatic complaints) and externalized (aggressiveness, disobedience, destructiveness, hyperactivity, impulsivity) [13]. ADHD is already classified according to DSM 5 [14] as a neurodevelopmental disorder along with ASD (autistic spectrum disorder); although it shares more comorbidities with disturbing behavioral and impulse control disorders, in which there is oppositional defiant disorder, intermittent explosive disorder, and dissocial (or behavioral) disorder. Personally I find this change complicated in DSM because with the previous classification it was easier to explain to parents that behavioral disorders in children under 6 years are grouped in neurodevelopmental disorders and after 6 years old, when delays have not been corrected, when neuropsychological and psychometric assessments can already be made, when in theory behavioral molding is advanced in its process; then there would be more conclusive data on intellectual disabilities or behavioral disturbances and their comorbidities. In addition, it is when the pharmacotherapy directed as are the stimulants and nonstimulants of the CNS are allowed [15]. The multimodal treatment should always be recommended and the pharmacological only if necessary, we must remember that the success in treatment is always based on the correct diagnosis. It is not advisable to initiate "routine" psychopharmacological treatment in any child with difficulties. Nor is it advisable to give up absolutely the benefits of a treatment of this nature when the picture so requires, and its use solves the problem of children [16]. Therefore, the concern of an appropriate evaluation, to reduce the risk of making mistakes in diagnoses and treatments.

\section{Methodology}

We reviewed the medical records of patients who came for a behavioral problem and determined according to DSM IV / DSM 5 whether they met criteria for a behavioral disturbance disorder and impulse control or some neurodevelopmental disorder. Determining age, sex, behavioral or other symptomatology reported by parents; neurological examination; and we included as diagnostic impressions: ADHD, oppositional defiant disorder, anxiety disorder, autism spectrum disorder and detection of comorbidities. In conclusion, how many patients came for behavioral problems; of whom met criteria for diagnosing a neurobiological disorder, and if there were rules and habits at home as suspected of a disorder in the child rearing structure home environment.

This is an observational, descriptive and transversal study, based on empirical observations from outpatient patients at the General Hospital of Tijuana and Neuromedica. We selected patients who were applied a DSM IV / 5 criteria questionnaire; 66 patients were selected, who referred as behavioral problems, between 2 and 6 years old, in the period between 2014 and 2015. 53 patients were children (80\%) and 13 were girls (19\%). 62\% said they had no rules and habits at home and $38 \%$ said they had rules and habits in their home environment (Table 1).

Table 1: Reason for Consultation.

\begin{tabular}{|c|c|c|c|c|}
\hline & Frecuencia & Porcentaje & Porcentaje Valido & Porcentaje accumulado \\
\hline Behavior problems & 42 & 63,6 & 63,6 & 63,6 \\
\hline Hyperactivity & 11 & 16,7 & 16,7 & 80,3 \\
\hline Aggressiveness & 4 & 6,1 & 6,1 & 86,4 \\
\hline Tantrums & 2 & 3,0 & 3,0 & 89,4 \\
\hline Impulsiveness & 1 & 1,5 & 1,5 & 90,9 \\
\hline Anxiety & 1 & 1,5 & 1,5 & 92,4 \\
\hline Irritability & 5 & 7,6 & 7,6 & 100,0 \\
\hline Total & 66 & 100,0 & 100,0 & \\
\hline
\end{tabular}

The reason for consultation was observed in $100 \%$ of the patient's behavioral problems. 42 patients referred for unspecified behavior problems, 11 hyperactivity, 5 irritability, 4 aggressive, 2 tantrums, 1 for impulsivity and 1 for anxiety.

DSM IV / 5 criteria were used in the form of a questionnaire for the parents, corroborated in medical consultation and completed with developmental research and complete neurological examination.

\section{Results}

18 of 66 patients (27\%) met criteria for comorbid hyperactivity disorder (among the most common comorbidities: oppositional defiant disorder 8 patients, anxiety 5 patients, dissocial disorder 4 patients, dyspraxia 2 patients, epilepsy 5 patient, Kempe syndrome 1 patient)

Only 5 patients $(7 \%)$ met criteria for ADHD without comorbidities.

5 patients (3\%) oppositional defiant disorder.

2 patients (3\%) anxiety disorder.

13 patients (19\%) met criteria for Autism spectrum disorder.

28 patients $(42 \%)$ did not meet criteria for a behavioral disturbance disorder and impulse control or neurodevelopment (Figure $1 \& 2$ ). 


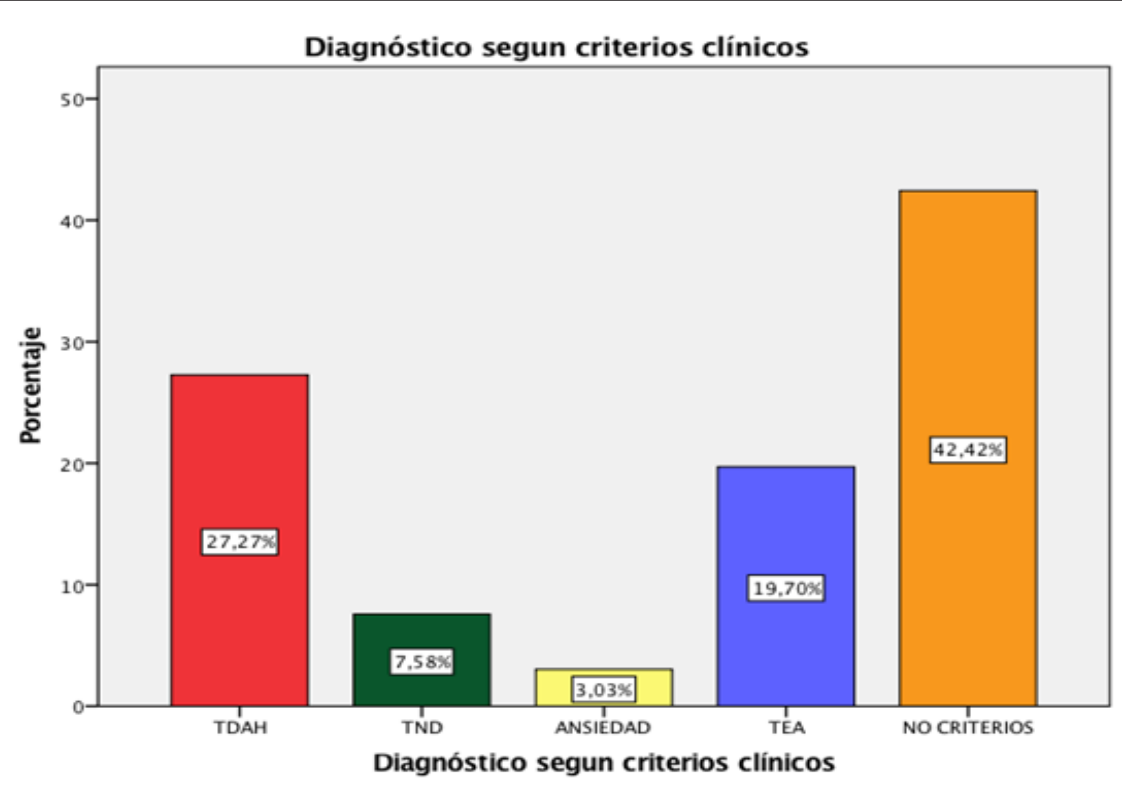

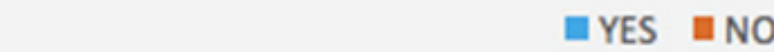

9

Comorbid

ADHD

$\square$ YES $\square$ NO

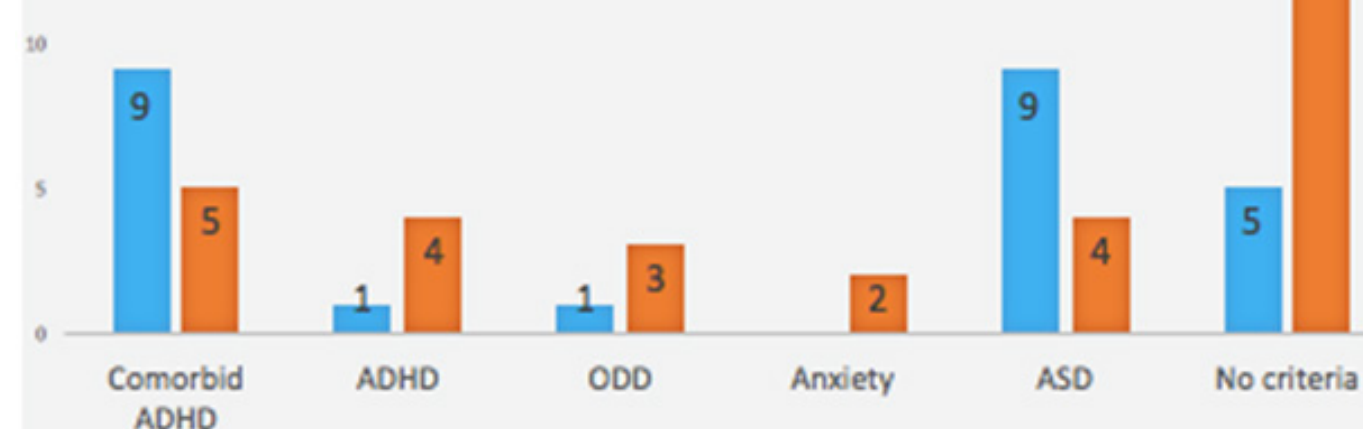

2. ARE THERE RULES AND HABITS AT HOME?

\section{Conclusions}

1. Almost half of the patients (42\%) did not meet the clinical criteria for a neurobiological disorder or disruptive behavior. This percentage is the one that is at risk of being over diagnosed and maybe the misconduct problem could be related to the child's rearing home environment instead of having a neurobiological disorder.

2. $27 \%$ of the patients were diagnosed with ADHD, $19 \%$ were comorbid ADHD and only 7\% ADHD were without comorbidities; which makes us do an exhaustive anamnesis of all the conduct symptoms avoiding then sub diagnosis of such comorbidities.
3. Due to the child's brain is under construction in the early stages of life, it is important to perform good parenting and positive molding before establishing diagnoses or treatments that may become inadequate.

4. More studies, especially preschooling, are needed to determine if the behavioral problem continues despite establishing a good parenting structure. There is not enough data in the literature.

\section{References}

1. J Sasot Llevadot, Ibáñez Bordas RM, Soto López A, Montañés Rada F, Gastaminza Pérez X, et al. (2015) GEITDAH consensus on conduct disorders in children and adolescents. Rev Neurol 61 (4): 167-182. 
2. Reitman D, Currier RO, Hupp SD, Rhode PC, Murphy MA, et al. (2001) Psychometric characteristics of the parenting scale in a head start population. Journal of clinical child psychology 30(4): 514-524.

3. Cuervo M Angela (2010) Parenting styles and socio affective development in childhood. Diers Perspect Psicol 6(1): 111-121.

4. Castilllo A (2002) Prácticas de crianza de riesgo y problemas de conducta en los hijos. Apuntes de psicología 20(2): 7.

5. Barker E, Oliver B, Maughan B (2010) Co-occurring problems of early onset persistent, childhood limited, and adolescent onset conduct problme youth. J Child Psichology ang Psychiatry 51(11): 1217-1226.

6. Pardini D, Fite PJ (2010) Symptoms of conduct disorder, oppositional defiant disorder, attention deficit/hyperactivity disorder, and callousunemotional traits as unique predictors of psychosocial maladjustment in boys: Advancing an evidence base for DSM-V. J Am Acad Child Adolesc Psychiatry 49(11): 1134-1144.

7. Winders D, P Gail Williams (2011) Attention déficit / hyperactivity disorder in preschool age children: Issues and concerns. Clinical pediatrics 50(2): 144-152.

8. Barragán Pérez E, de la Peña Olvera F, Ortiz León S, Ruiz García M, Hernández Aguilar J, et al. (2007) Primer consenso latinoamericano de trastorno por déficit de atención e hiperactividad. Bol Med Hosp Infant Mex 64(5).
9. Julio César Flores Lázaro , Feggy Ostrosky Solís (2008) Neuropsicología de Lóbulos Frontales, Funciones Ejecutivas y Conducta Humana. Revista Neuropsicología Neuropsiquiatría y Neurociencias Abril 8(1): 47-58.

10. Volkow ND, Swanson JM (2013) Adult attention-deficit hyperactivity disorder. New Engl J Med 369(20): 1935-1944.

11. Valera EM, Faraone SV, Murray KE, Sedman Lj (2007) Meta-analysis of structural imaging findings on attention-deficit hyperactivity disorder. Biol Psychiatry 61(12): 1361-1369.

12. Fernandez D, Fernandez A, Garcia J, Quiñones D (2010) Neuroimagen en el trastorno por déficit de atención/hiperactividad. Rev Neurol 50(Supl 3): S125-S133.

13. Mazadiego T, Vera A, Ruiz S (2011) Internallzed and externallzed problems In a sample of elementary school children. J Behav Healt \& Social Issues 3(1).

14. Diagnostic and Statistical Manual of Mental Disorders (DSM), fifth edition. American Psychiatric Association.

15. May DE, Kratochvil CJ (2010) Attention-deficit hyperactivity disorder: recent advances in paediatric pharmacotherapy. Drugs 70(1): 15-40.

16. Gratch (2009) El trastorno por deficit de atención. 2da edición. Panamericana. 